\title{
Erratum to: Silent Aspiration Risk is Volume-dependent
}

\author{
Stevan B. Leder • Debra M. Suiter • \\ Barry G. Green
}

Published online: 21 June 2011

(C) Springer Science+Business Media, LLC 2011

\section{Erratum to: Dysphagia}

DOI 10.1007/s00455-010-9312-2

There is a typographical error in Table 1, the $X$ by Females and the $X$ by Males should have a bar over the $X$ to denote mean. The corrected Table 1 is given below.

Table 1 Participant demographics

\begin{tabular}{ll}
\hline Gender $^{\mathrm{a}}$ & \\
Females & $N=1780(43.5 \%)$ \\
Males & $N=2314(56.5 \%)$ \\
Age $^{\mathrm{b}}$ & $\bar{X}=70.30$ years (range $=2.0-105.0$ years) \\
Females & $\bar{X}=66.27$ years (range $=2.2-105.0$ years) \\
Males &
\end{tabular}

${ }^{a}$ Data are missing for $8(0.2 \%)$ participants

b Data are missing for $20(0.5 \%)$ participants

The online version of the original article can be found under doi:10.1007/s00455-010-9312-2.

S. B. Leder $(\varangle) \cdot$ B. G. Green

Department of Surgery, Section of Otolaryngology,

Yale University School of Medicine, P.O. Box 208041,

New Haven, CT 06520-8041, USA

e-mail: steven.leder@yale.edu

D. M. Suiter

Veterans Affairs Medical Center, Memphis, TN 38104, USA

B. G. Green

The John B. Pierce Laboratory, New Haven, CT, USA 